\title{
Semitendinosus Autograft Augmentation for a Patella Tendon Rupture after BTB ACL Reconstruction
}

\author{
Stephen Iacono MD, Matthew Moralle* MD, Balazs Galdi MD \\ Department of Orthopedics, USA
}

Submission: April 26, 2017; Published: May 09, 2017

*Corresponding author: Matthew Moralle, Department of Orthopedics, Rutgers New Jersey Medical School. Newark NJ. 90 Bergen St. D0C 7300. Newark NJ 07103, USA, Tel: 9084892544; Email: mailto:mrmoralle@gmail.com

\section{Introduction}

Patellar tendon rupture is a rare, but major event that often requires surgical repair in order to reestablish function of the extensor mechanism of the knee. Rupture of the tendon usually occurs in the 3rd or 4th decade of life and results from slip and fall accidents, or powerful contraction of the quadriceps such as during sporting events or weight lifting [1-3]. Anterior Cruciate Ligament (ACL) reconstruction using the central $1 / 3 \mathrm{rd}$ of the patellar tendon has been associated with rupture of the patellar tendon however this event is exceedingly rare occurring in less than $1 \%$ of all cases performed [1]. In the event of previous ACL repair, patellar tendon rupture usually occurs in a short time period after ACL reconstruction [4]. Comorbidities including diabetes mellitus (DM), systemic lupus erythematous (SLE) and chronic steroid use have been shown to precipitate rupture of the patellar tendon [5]. Patellar tendon rupture many years after ACL reconstruction has been sparsely studied in literature thus there is no consensus on the best method of repair. Some data suggests that late rupture of the patellar tendon following surgical harvesting of a portion of the tendon is due to devascularization, remodeling and weakening of the patellar tendon [4]. This case report involves a patient with acute patellar tendon rupture over 10 years after reconstruction of ACL. Augmentation of patellar tendon repair has been shown to have superior strength of repair as well as restored quadriceps strength and Range of Motion (ROM) [2,3,5]. There were no reported complications in the immediate post operative period and the patient was able to be discharged to home with a brace and crutches post op day three.

\section{Case Report}

Patient, CS, is a 38-year-old male who presented to the Emergency Department of a large academic institution with complaints of leg pain, inability to bear weight and inability to extend leg at the knee. He reports that he was playing basketball the night before and fell on his knee. At that time he felt a pop and was unable to bear weight. His past history is significant for a right knee ACL reconstruction with bone-patellar-bone autograft in
2000. Prior to inciting events, he denied any knee pain, numbness or tingling in lower extremity. He was admitted to the orthopaedic service under suspicion of ruptured patellar tendon and planned for operative repair. Pre-operative radiographs showed no fracture, dislocation or effusion. $\mathrm{X}$ ray of right knee showed evidence of ACL reconstruction with interference screws in distal femur and proximal tibia (Figures $1 \& 2$ ), as well as bone graft seen in tibial and femoral tunnel. There was no interruption of the ACL or PCL. CT showed a full thickness tear of the lateral aspect of patellar tendon at its insertion on the inferior pole of the patellar as well as central defect of the patellar tendon (Figures $3 \& 4$ ). The central defect is consistent with harvesting of central third of patellar tendon, used in ACL reconstruction.

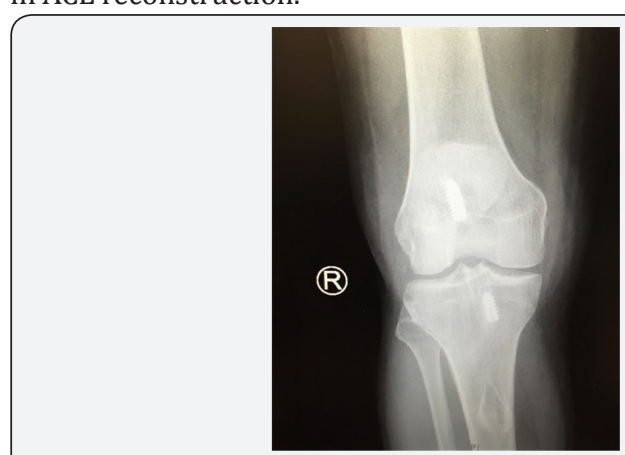

Figure 1: Pre Operative AP Knee X Ray.

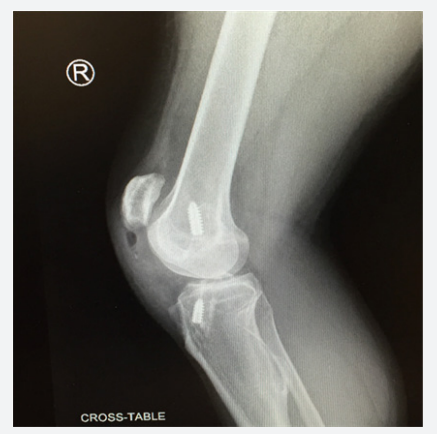

Figure 2: Pre operative Lateral Knee X Ray. 


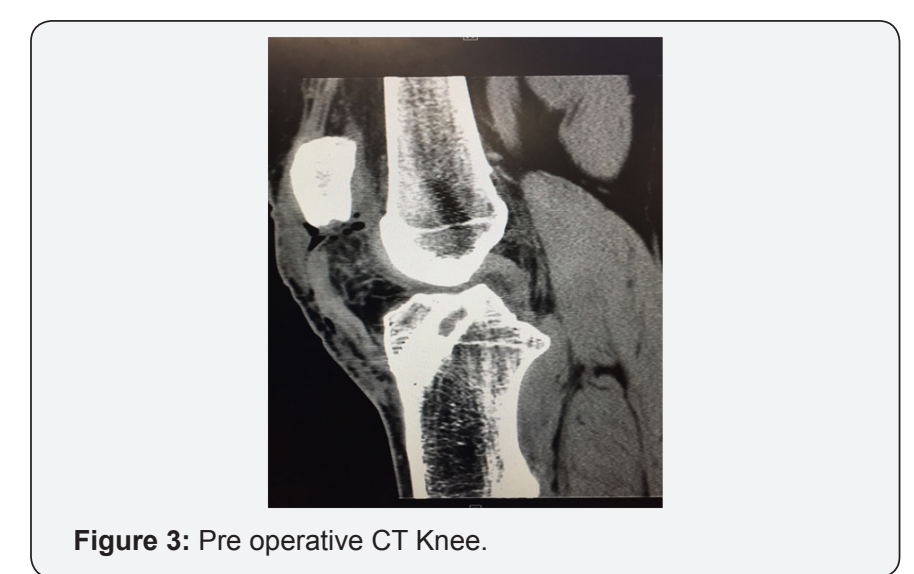

Figure 3: Pre operative CT Knee.

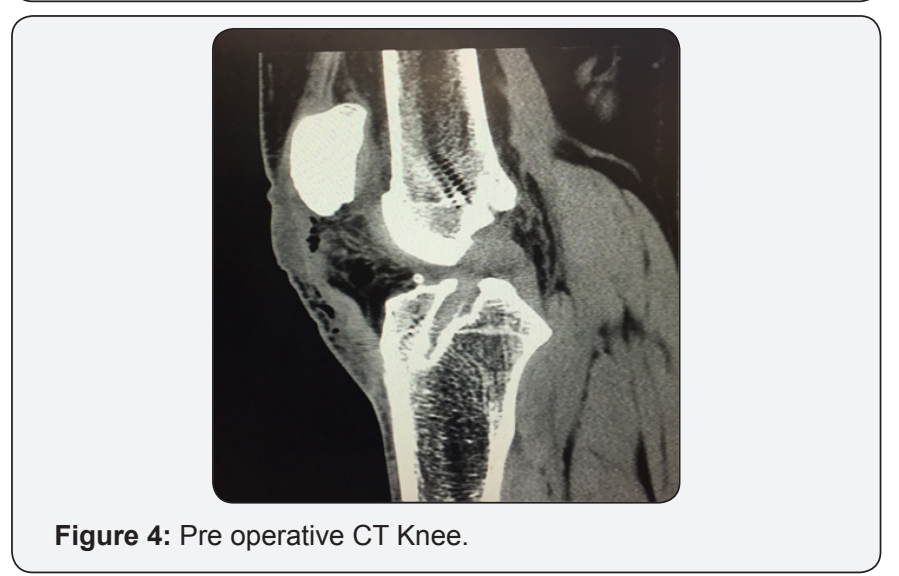

Operative repair of the patellar tendon was planned. Since the patient was known to have diminished integrity of the patellar tendon secondary to its use in ACL repair, it was decided that augmentation of the patellar tendon with semitendinosus tendon allograft was appropriate. A $15 \mathrm{~cm}$ midline incision was made over anterior aspect of right knee. Full thickness flaps were raised and dissection continued until patella and patellar tendon was exposed. The patient had a complete rupture of patellar tendon from patella. The central $1 / 3$ of patella tendon was confirmed to be missing, consistent with previous surgery. The semitendinosus was identified on the anteromedial tibia and was isolated from surrounding structures. The tendon was then harvested. A $5.5 \mathrm{~mm}$ tunnel was drilled into patella to fit harvested tendon.

A guide wire was placed through center of patella and a cannulated reamer was used over guide wire and semitendinosus tendon was passed through in a medial to lateral fashion. Once the autograft was in place, three drill holes were made in the central, medial and lateral portions of the patella. The patellar tendon was sutured to patella using \#5 Fiberwire sutures in a Krackow fashion. The sutures were then passed through the bone tunnels of the patella. The knee was placed in extension and the medial and lateral sutures were tied to themselves. The autograft tendon was placed in a figure of eight fashion and sutured to itself and the native patellar tendon to augment repair (Figure 5). Once the autograft tendon was sutured in place, the knee was placed in 90-degreeflexion, and no gaping was noted at repair site. The wound was thoroughly irrigated with saline. The subcuticular and skin were closed with 2-0 Vicryl and 3-0 Nylon respectively and the sterile dressing was applied. The leg was placed in a hinged knee brace locked in extension.

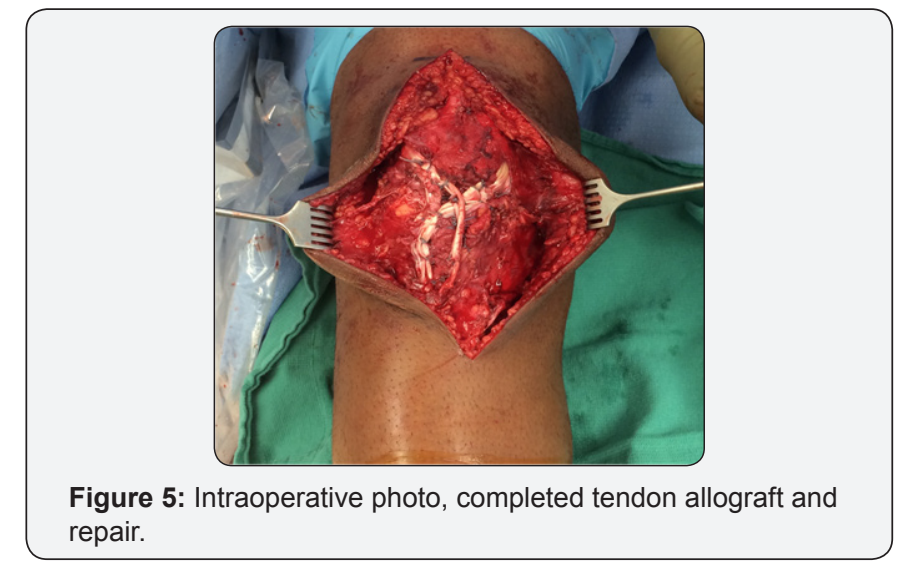

Patient recovered from surgery and anesthesia without complication. On post op day one he was able to ambulate several steps with assistance of crutches and PT. The patient began physical therapy regimen at four weeks after surgery and remained in knee brace locked in extension for two months after surgery. At the three-month follow up, the patient's pain is well controlled and he is ambulated without assistive devices. At most recent visit, the patient is able to straight leg raise, has $4+/ 5$ strength with knee flexion/extension and has range of motion of $0-120^{\circ}$. X rays taken after three months show previous ACL tendon repair is unchanged, patellar tendon repair is and allograft is intact (Figures $6 \& 7$ ). At twelve month follow up, the patient has full range of motion and strength symmetric to contralateral side and has returned to normal work and sport activities.

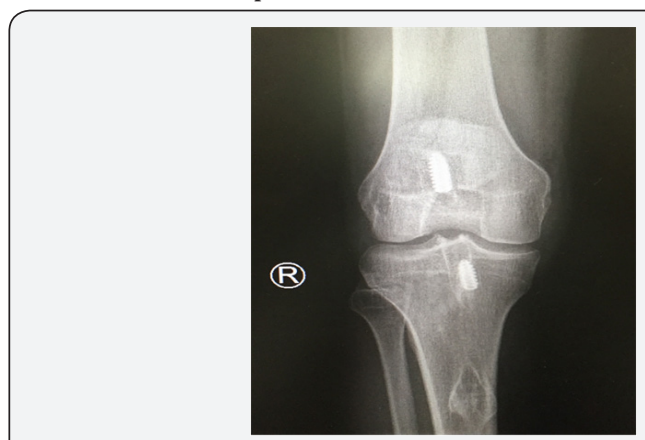

Figure 6: Three month Post Operative AP Knee X Ray.

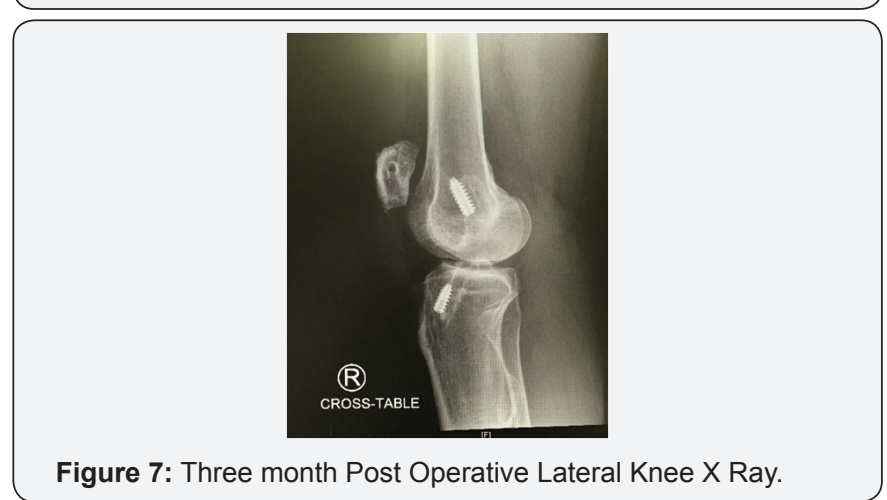




\section{Discussion}

The majorities of patellar tendon ruptures occur shortly after ACL reconstruction and are attributed to trauma in the post operative period. This case is unusual since the presented patient has a reconstruction of the ACL using ipsilateral patellar tendon for reconstruction over 10 years ago and never experienced complications with his knee prior to the accident. Additionally, the patient had no comorbidities associated with patellar tendon rupture such as DM, SLE or steroid use. In our search, we were only able to come across one case of patellar tendon rupture following BTB ACL reconstruction ten years prior [6].

The literature describes several established techniques to repair torn $\mathrm{ACL}$, these techniques include autogenous graft of ipsilateral or contralateral central 1/3rd of the patellar tendon [7]. Patella fracture after ACL reconstruction using the patella tendon autograft has been reported in the literature at a rate of $1.3 \%$ in 618 consecutive patients [8]. However, no such fracture was reported in this case. Although there is an association between the use of the central third of the patellar tendon and tendon rupture, there is little evidence of a significant increase in acute events following ACL reconstruction [1]. According to Benner et al. [1] the incidence of patellar rupture after Bone-Tendon-Bone (BTB) ACL reconstruction is $0.24 \%$ in a database of over 5000 patients and usually occurs in the distal portion of the tendon. Since acute patellar rupture after ACL repair is extremely rare, there is little evidence on the best methods of repair and repair outcome $[1,4]$. In the case of native patellar tendon tear, management is dependent on the severity of the lesion. In the most conservative treatment, the affected knee can be braced in extension with or without physical therapy support. When surgical intervention is necessary, primary repair using non absorbable sutures in a Krackow fashion with cerclage has shown to be an effective method of treatment with excellent functional result [9]. However, in the event of patellar rupture after previous BTB ACL revision, surgery is always required to reestablish function of the patellar tendon $[5,10]$. Repair of the patellar tendon after BTB ACL reconstruction usually requires the augmentation of the repair.

Patellar tendon repair with augmentation can be accomplished by several techniques including using wires, autogenous or allogenous grafting. In a large study Gilmore et al. [2] demonstrated that semitendinosus graft was the most popular graft choice, and was used in $41 \%$ of patients with chronic patellar tendon rupture, or rupture after ACL reconstruction. Augmentation of patellar tendon with semitendinosus graft has been well documented by Ecker et al. [11] since 1979. Autogenous grafting of the semitendinosus has been demonstrated as having superior outcomes in terms of strength of repair, ROM after surgery and return to normal functional status $[2,3,5]$. Patients who receive repair with augmentation have shown to have greater ROM from $0^{-}-129$ o when compared to patients who received primary repair alone which showed ROM of $-11^{\circ}$ to $102^{\circ}$ [2]. Additionally long term follow up of patients show that strength of repaired tendon is comparable to uninjured knee [3].
Early mobilization, as well as aggressive physical therapy is key for improved functional outcome in patients who have patellar tendon repair [12].

\section{Conclusion}

Late patellar tendon rupture following BTB ACL reconstruction is an extremely rare event and there is little data that indicates which techniques are appropriate for reconstruction. This patient received patellar tendon repair with augmentation using the semitendinosus tendon. We believe that this technique will provide the patient with the best possible functional outcome and return to normal activity. After 12 months of follow-up, the patient continues to make good progress in motor strength as well as ROM consistent with previously reported results. The semitendinosus augmentation is an adequate technique for patellar tendon repair in patients with BTB ACL reconstruction.

\section{References}

1. Benner RW, Shelbourne KD, Urch SE, Lazarus D (2012) Tear patterns, surgical repair, and clinical outcomes of patellar tendon ruptures after anterior cruciate ligament reconstruction with a bone-patellar tendonbone autograft. Am J Sports Med 40(8): 1834-1841.

2. Gilmore JH, Zoë J Clayton-Smith, Marc Aguilar, Spiros G Pneumaticos, Peter V Giannoudis (2015) Reconstruction techniques and clinical results of patellar tendon ruptures: Evidence today. Knee 22(3): 148-55.

3. Nguene-Nyemb AG, D Huten, M Ropars (2011) Chronic patellar tendon rupture reconstruction with a semitendinosus autograft. Orthop Traumatol Surg Res 97(4): 447-450.

4. Marumoto JM, Richardson AB, Medoff RJ, Mayfield GW (1996) Late patellar tendon ruptures after removal of the central third for anterior cruciate ligament reconstruction. A report of two cases. Am J Sports Med 24(5): 698-701.

5. Cadamb A, GA Engh (1992) Use of a semitendinosus tendon autogenous graft for rupture of the patellar ligament after total knee arthroplasty. A report of seven cases. J Bone Joint Surg Am 74(7): 974-979.

6. Haasters F. Ockert B, Mutschler W, Kessler MA (2009) [Late patellar tendon rupture 10 years after anterior cruciate ligament reconstruction using a bone-patellar tendon-bone graft]. Unfallchirurg 112(8): 728-733.

7. Busfield BT, MR Safran, WD Cannon (2005) Extensor mechanism disruption after contralateral middle third patellar tendon harvest for anterior cruciate ligament revision reconstruction. Arthroscopy 21(10): 1268.

8. Drez DJ, DeLee J, Holden JP, Arnoczky S, Noyes FR, et al. (1991) Anterior cruciate ligament reconstruction using bone-patellar tendonbone allografts. A biological and biomechanical evaluation in goats. Am J Sports Med 19(3): 256-263.

9. Siwek CW, JP Rao (1981) Ruptures of the extensor mechanism of the knee joint. J Bone Joint Surg Am 63(6): 932-937.

10. Bek D, B Demiralp, M Kömürcü, A Şehirlioğlu (2008) Neglected patellar tendon rupture: a case of reconstruction without quadriceps lengthening. J Orthop Traumatol 9(1): 39-42. 
11. Ecker ML, PA Lotke, RM Glazer (1979) Late reconstruction of the patellar tendon. J Bone Joint Surg Am 61(6A): 884-886.

This work is licensed under Creative Commons Attribution 4.0 License

DOI: $10.19080 /$ OROAJ.2017.06.555698
12. Larson RV, PT Simonian (1995) Semitendinosus augmentation of acute patellar tendon repair with immediate mobilization. Am J Sports Med 23(1): 82-86.

\section{Your next submission with Juniper Publishers will reach you the below assets}

- Quality Editorial service

- Swift Peer Review

- Reprints availability

- E-prints Service

- Manuscript Podcast for convenient understanding

- Global attainment for your research

- Manuscript accessibility in different formats

( Pdf, E-pub, Full Text, Audio)

- Unceasing customer service

Track the below URL for one-step submission https://juniperpublishers.com/online-submission.php 